\title{
Educación artística-visual en niños indígenas vulnerables. Una investigación cualitativa sobre su desarrollo artístico y curricular
}

\author{
Visual Artistic Education in Vulnerable Indigenous \\ Children. A Qualitative Research about its Artistic \\ and Curricular Development
}

María Fernanda Álvarez Gil*

\section{RESUMEN}

En este trabajo se busca demostrar de qué manera la educación artística-visual puede ser un factor de desarrollo en los ámbitos artístico y curricular de infancias indígenas socioeconómicamente vulnerables. Con base en una metodología de corte etnográfico, con un doble estudio de casos correspondientes a dos grupos de $2^{\circ}$ grado de primaria de dos contextos diferentes, se expone cómo se pueden estimular y mejorar los aprendizajes y el desempeño de los alumnos por medio de intervenciones educativas de esta índole en el aula de una escuela indígena urbana y en el de una rural. El estudio se sustenta teórica y prácticamente en dos importantes corrientes de la educación artística, la expresiva por la paz y la educación a través del arte, para implementar y evaluar diversas actividades que impactan en los dos ámbitos arriba mencionados. Se concluye, a través de una comparativa de los estudios de caso en ambos contextos, el indígena urbano y el rural, sobre las similitudes y diferencias que dan cuenta de los alcances positivos de la creación artística en los niños de estas localidades, así como de las limitaciones de la investigación.

Palabras clave: infancias indígenas, grupos vulnerables, etnografía educativa, educación artística, intervención educativa

\section{ABSTRACT}

In this work, we seek to demonstrate how artistic-visual education can be a factor of development in the artistic and the curricular spheres of socio-economically vulnerable indigenous children. With an ethnographic methodology with a double study of cases corresponding to two second grade groups of elementary schools in two different contexts, it is explained how to stimulate and improve learning and student performance through educational-artistic interventions in the classroom in an urban and a rural indigenous school. The study is supported theoretically and practically by two relevant currents the artistic education, the expressive for peace and the education through art, to implement and evaluate diverse activities that impact in the two above-mentioned areas. It is concluded, through a comparison of the case studies in both contexts -the urban indigenous and the rural-, on the similarities and differences that refer the positive reaches of the artistic creation in the children of these localities, as well as of the limitations of the investigation.

Key words: indigenous children, vulnerable groups, educational ethnography, artistic education, educational intervention

\footnotetext{
*Universidad Iberoamericana, Ciudad de México, México; feralvarezgil@gmail.com
} 


\section{INTRODUCCIÓN}

El propósito principal del artículo es exponer, a partir de una investigación cualitativa, de qué manera la educación de las artes visuales puede fomentar y mejorar el desarrollo artístico y académico de los niños de contextos indígenas urbanos y rurales socioeconómicamente vulnerables.

El trabajo está encaminado a generar y probar propuestas pedagógicas y didácticas en el campo de la educación artística que favorezcan la formación de las niñas y de los niños de México en contextos particulares.

Para llegar a ello, se establece en un primer momento el marco metodológico basado en la etnografía educativa y que incluye dos estudios de caso comparativos en una escuela indígena urbana de Chimalhuacán, Estado de México y en una rural de Malinaltepec, en la montańa de Guerrero, con intervenciones artísticas-educativas, cuestionarios, entrevistas, descripción densa

$230 y$ diarios de campo. En un segundo momento se explica el marco teórico sustentado en las dos corrientes de educación artística que fundamentaron el estudio. Se detalla la comparativa de lo arrojado en ambos contextos con ejemplos de su aplicación práctica para, finalmente, analizar las conclusiones, los aportes y las limitaciones de la investigación.

\section{METODOLOGÍA: LA ETNOGRAFÍA COMO UN ENFOQUE TEÓRICO-METODOLÓGICO}

El enfoque metodológico de la investigación fue etnográfico, con doble estudio de casos comparativos y contrastados; éstos incluyen, a su vez, intervenciones artísticas-educativas que, en realidad, fueron una parte medular de la práctica y múltiples instrumentos de recolección de datos como diario de campo, entrevistas, cuestionarios y registros varios como fotografías, grabaciones y videos, todo ello para ser analizado e interpretado desde un punto de vista cualitativo, pero que puede incluir procesos de razonamiento cuantitativos. 
EDUCACIÓN ARTÍSTICA-VISUAL EN NIÑOS INDÍGENAS VULNERABLES. UNA INVESTIGACIÓN...

\section{Etnografía educativa con doble estudio de casos}

Más que un método, se considera aquí la etnografía como un enfoque y postura teórico-metodológica en el sentido de que el trabajo de campo, la recolección de información y sus herramientas, los análisis e interpretaciones parten de los sujetos involucrados e investigados a quienes se busca dar voz y presencia a lo largo de la investigación, desde las micro-historias hasta posibles alcances teóricos mayores. La etnografía es tomada tal como la concibe Elsie Rockwell (2009) en La experiencia etnográfica. Historia y cultura en los procesos educativos pues, como la autora sugiere, el estudio etnográfico recupera relatos no escritos ni documentados, es decir, historias de lo cotidiano que, en sus aproximaciones y diferencias con otros cotidianos de otras localidades y culturas, genera y produce conocimientos y líneas de investigación que no aparecerían en otras maneras de investigar. El estudio etnográfico con las comunidades educativas puede arrojar mucha luz sobre la relevancia de los contextos en los procesos de enseñanza-aprendizaje, sus características, posibles idiosincrasias, sus fortalezas y debilidades, su estructura y manera de ver la vida, así como sus vivencias y apropiación del conocimiento.

Importa señalar que la etnografía contemporánea se deriva del poscolonialismo y se encuentra dividida en dos momentos claves que definen su cronología y práctica: la modernidad y la posmodernidad. En la época moderna, derivada de la Ilustración, prevaleció en su característica búsqueda de la igualdad y la felicidad humanas, sustentadas en el progreso y en adelantos científicos basados en el positivismo, la visión universalista, homogénea y objetivista del ser humano eurocéntrico como modelo a seguir y que se pretendió formar e implementar en todas las sociedades y culturas, fueran occidentales o no. Este modelo, por otra parte, demostró su fracaso frente a barbaries tales como las grandes guerras mundiales y el holocausto judío, entre otras, como bien lo analizara la escuela de Frankfurt, ya que esta fe en la ciencia y el cientificismo no resolvió la cuestión ética y la maldad humanas sino, por el contrario, generó mecanismos cada vez más sofisticados para la destrucción masiva de seres humanos y del medio ambiente. Esto, por supuesto, tuvo implicaciones diversas 
en la antropología y este modelo homogéneo, al buscar imponerse en sociedades conformadas económica, estructural, ideológica y cosmogónicamente distintas a las hegemónicas, nunca llegó a concretarse ni a consolidarse en ellas. Ello dio lugar a lo que hoy identificamos como el paradigma posmoderno para entender y explicar, entre otras cosas, diferentes ámbitos del quehacer humano en diversas latitudes y que se erige como un sistema reivindicador de lo cualitativo, lo particular, lo minoritario, lo multicultural y lo único, frente a lo que Lyotard (2006) calificó críticamente como los grandes relatos de verdades totalizantes, absolutistas y muchas veces etnocéntricas provenientes de la tradición moderna de Occidente. La objetividad del cientificismo positivista en el paisaje de vidas y mundos occidentales económicamente más desarrollados, que en el área de investigación académica se refleja en el uso de metodologías y enfoques únicamente cuantitativos, no puede ya imponerse tan categóricamente frente a relatos subjetivos, relativistas e inscritos en contextos únicos o poco comunes de otros universos culturales y la etnografía posmoderna es testigo de ello. Además de que estos contextos, a causa de la globalización de las sociedades, la migración y el desarrollo del mundo tecnológico, cada vez son más interdependientes, híbridos y se encuentran más mezclados.

Dentro de las corrientes etnográficas actuales y posmodernas, James Clifford (2001) define, en su texto "Sobre la autoridad etnográfica”, varias vertientes de la etnografía que rompen con la verticalidad, unilateralidad y uniformidad del modelo moderno y entre las que se encuentra la que se conoce como polifonía etnográfica, que es la que se utilizó en este estudio.

Los estilos fragmentados de hacer etnografía y esta polifonía responden a una mayor atención prestada a todo tipo de documentos, pero sobre todo a la visibilidad, valorización y dignidad cada vez mayores que se otorga a los sujetos estudiados; de la misma forma, brindan un espacio abierto a la pluralidad de voces, sobre todo cuando éstas provienen del contexto que se está investigando. Es una práctica mucho más horizontal en relación con las etnografías colonialistas y modernistas aún ancladas en visiones unilaterales de verdades racionalistas occidentales unívocas: 
Es intrínseco a la quiebra de la autoridad monológica que las etnografías ya no se dirijan más a un único tipo de lector: la multiplicación de lecturas posibles refleja el hecho de que la conciencia "etnográfica" ya no puede ser vista como monopolio de ciertas culturas y clases sociales de Occidente... Con el reciente cuestionamiento de los estilos coloniales de representación, con la expansión de la alfabetización y la conciencia etnográfica, están surgiendo nuevas posibilidades para la lectura $-\mathrm{y}$, por lo tanto, para la escritura- de descripciones culturales (Clifford, 2001, p. 73).

Todo ello es parte de la polifonía que, formalmente, refleja estos otros mundos y realidades estudiados, que ya no pueden ser vistos como un todo homogéneo y unificado, o desde un sólo ángulo o lectura a la manera colonial y moderna más uniformizante. La verdad única moderna occidental es relativizada, así como las voces que narran sus historias y que responden a los pequeños discursos, que hacen contrapeso a los grandes relatos que denunciara Lyotard (2006) y que, en el caso de esta indagación, se materializan a través de los pequeños relatos creativos y visuales que niños indígenas urbanos y rurales en situación de vulnerabilidad realizaron a través de la educación artística.

\section{Los estudios de caso}

\section{El estudio de casos}

Dentro del enfoque etnográfico educativo como principal perspectiva teórica-metodológica en la que se encuadra la investigación, se utilizó el estudio de casos como modelo metodológico por el carácter exploratorio y particular de la misma, aunado a la profundidad buscada en determinados lapsos de tiempo. La investigación cualitativa, en general, y los estudios de caso, en particular, indagan siempre en conocimientos que los enfoques más positivistas no pueden generar y que provienen de la búsqueda de información en el terreno donde acontecen los fenómenos estudiados.

Las palabras de R. E. Stake (2010, p. 277) sobre el estudio de casos esclarecen muy bien la selección de este método, ya que, como él dice: 
El estudio de casos es el estudio de la particularidad y de la complejidad de un caso singular para llegar a comprender su actividad en circunstancias importantes... observa de un modo naturalista e interpreta las interrelaciones de orden superior en el interior de los datos observados ... Si bien otros estilos de investigación buscan elicitar relaciones generales, el estudio de casos explora el contexto de las instancias individuales.

Se trata, de nuevo, en el campo educativo, del método de lo particular, de los pequeños universos cotidianos, de lo único, muy raro o incipiente (en este caso las intervenciones artísticoeducativas en aulas de determinados contextos sociales) que generó información exhaustiva y análisis e interpretaciones profundas $\mathrm{y}$ donde el contexto es sumamente importante.

Asimismo, Jaime Martínez Bonafé (1990), en su ensayo "El estudio de casos en la investigación educativa", establece tres dimensiones que se relacionan directamente con el tipo de investigación que aquí se presenta, lo mismo que sus enfoques, 234 perspectivas y ángulos, y explican muy claramente la elección y aplicación de este método de investigación en este trabajo. Éstas son la dimensión micro del sistema, en este caso dos grupos de $2^{\circ}$ de las escuelas y las interrelaciones y procesos que ahí se generan, sin descartar un posible alcance socioeducativo más amplio. La segunda dimensión destaca el carácter práctico y situacional del estudio de casos, es decir, el trabajo de campo con una visión humanístico-crítica de la diversidad, complejidad y multiplicidad de los fenómenos educativos que ahí se dan. La tercera dimensión enfatiza el aspecto subjetivo de la generación de significados que se suscitan en este tipo de estudios y que tiene que ver directamente con esta posible construcción, fortalecimiento o recuperación de identidades a través de la reivindicación del yo y de las subjetividades de los nińos por medio de la creación artística.

Cuando investiga dos grupos de dos escuelas indígenas de escasos recursos socioeconómicos, una urbana y una rural, éste es un estudio de casos múltiple, que toma cada escuela como un caso individual que después comparará y contrastará. 
EDUCACIÓN ARTÍSTICA-VISUAL EN NIÑOS INDÍGENAS VULNERABLES. UNA INVESTIGACIÓN...

\section{El estudio de casos múltiple, comparativo y contrastado}

El estudio de casos múltiple permite una mayor profundización y alcances en la investigación. La comparativa de constantes y variables de cada caso, así como de las interpretaciones individuales directas, aunadas a estudios contrastados entre los casos y sus especificidades, aumenta la densidad y diversidad de la información arrojada en cada caso, sub-caso y contexto, los puntos de vista y diferencias de los actores involucrados, la multiplicidad de productos creados, así como la posibilidad de interpretaciones mayores y trascendentes.

Para esta investigación lo que se hizo, a partir del primer estudio de casos en una escuela indígena urbana, fue una replicación condensada del modelo, diseño de actividades y recogida de datos que se aplicó en un segundo momento en una escuela indígena rural ya que, como lo explica el libro de Gregorio Rodríguez Gómez (1996, p. 96), en la replicación de estudio de casos:

... las evidencias presentadas a través de un diseño de casos múltiples son más convincentes, y el estudio realizado desde esta perspectiva es considerado más robusto (Yin, 1984) al basarse en la replicación, que la entendemos como la capacidad que se tiene con este tipo de diseńo de contestar y contrastar las respuestas que se obtienen de forma parcial con cada caso que se analiza.

Los dos contextos, aunque muy diferentes, son de alguna manera parecidos en cuanto a las condiciones socioeconómicas, la vulnerabilidad de sus poblaciones y su origen indígena, por lo que tendrán similitudes y contrastes abundantes que enriquecerán los análisis e interpretaciones subsecuentes de la investigación.

La replicación se realizó en la escuela rural, adaptándola al contexto a partir de lo hecho en Chimalhuacán y fue condensada e intensiva, es decir, que se aplicó en un lapso de dos semanas con dos seguimientos de otras dos semanas cada uno, es decir, seis semanas en total. Se usó el modelo de investigación ya empleado en la escuela urbana, pero seleccionado y sintetizado de acuerdo con lo ya probado en esta escuela y que resultó eficaz y pertinente 
para responder las preguntas de investigación. Se entiende esto como trabajo de campo condensado en el cual:

La evaluación corre al ritmo de los acontecimientos que estudia ... Se necesita un retrato de un caso y el tiempo sólo permite unos pocos días en el campo ... esta estrategia también ofrece la posibilidad de integrar el estudio de casos en esa gama del alcance de la mayoría de los investigadores que no pueden plantearse los laboriosos estudios de largo plazo al estilo clásico (Martínez Bonafé et al., 1990, p.72).

El estudio de casos en la escuela rural se condensó por motivos económicos y de tiempos que la investigadora no podía solventar. Se reprodujeron todas las actividades realizadas en la escuela indígena urbana, pero se seleccionaron los procedimientos de recolección de datos más eficientes ya utilizados en ésta y los otros se desecharon. De esta manera, la esencia misma de la investigación y su aplicación práctica no fue, en realidad, grandemente alterada en la escuela rural, sino únicamente en relación con las adaptaciones contextuales y la distribución de los tiempos, en vez de ir una vez a la semana durante un ciclo escolar, se acudió diariamente durante tres tandas de dos semanas cada una, en un lapso de tiempo que duró un mes y medio en total, es decir 30 sesiones de dos horas.

\section{Intervención artística-educativa}

Dentro de los estudios de casos -y como eje fundamental de la investigación- se encuentra la intervención artístico-educativa. Ésta se considera aquí como un modelo de acción práctica que, como la palabra lo indica, interviene de determinada manera en la secuencialidad de un proceso de enseńanza-aprendizaje y que, generalmente, cumple con un objetivo, que es el de transformar para mejorar en lo posible este proceso educativo. Lo realizado en esta investigación se puede inscribir en la intervención proactiva y grupal. Está definida por anticiparse a los problemas o situaciones, persigue objetivos previamente establecidos (en este caso, los desarrollos artísticos y curriculares en el aula) y está pensada para el conjunto de la población y no como necesidad exclusi- 
va de sujetos con problemas de diferente índole. En el caso de este estudio, se trata de actividades artísticas que se diseñan a partir de un tema del programa de estudios de la Secretaría de Educación Pública (SEP). Se platicaba con los maestros llegando a un acuerdo-diagnóstico sobre el tema o problemática curricular a trabajar, y luego se proponía una actividad de carácter creativa-artística que, transversalmente, incorporaba otras materias y conocimientos, además de los propiamente artísticos para, por último, interpretarse y analizarse.

El esquema siguiente explica la estructura y fases de estas intervenciones y su funcionamiento:

FIGURA 1. Estructura y fases de las intervenciones artístico-educativas realizadas en el aula

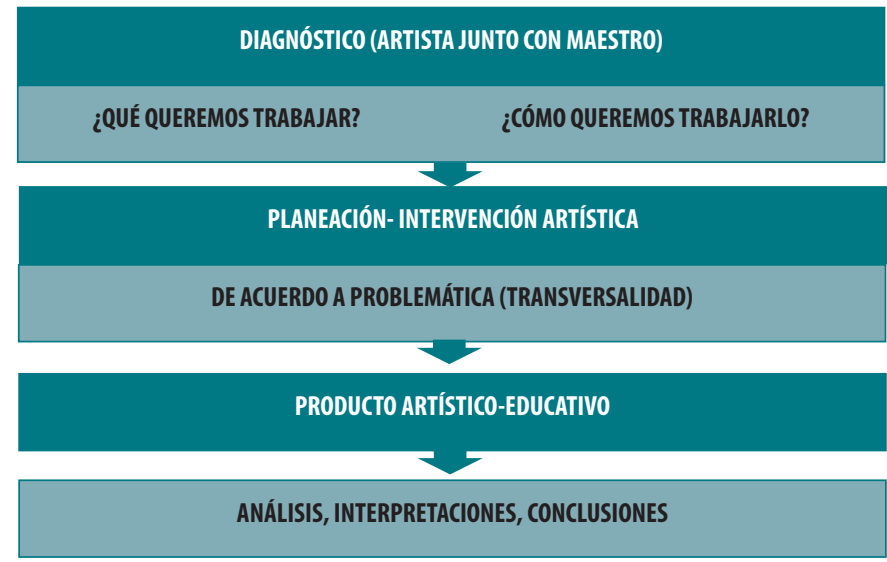

Al ser la información generada a partir de la experimentación y las vivencias directas de los niños a través de procedimientos artísticos, la investigación trató de determinar también el aprendizaje significativo provocado por estas intervenciones a nivel artístico y curricular. 


\section{INSTRUMENTOS METODOLÓGICOS PARA LA RECOLECCIÓN DE INFORMACIÓN}

Son varios los medios e instrumentos que se utilizaron para recabar datos como observación, entrevistas, cuestionarios, evaluaciones grupales, descripciones, diario de campo, fotografías, video y grabaciones de audio. Mucho de ello se realizó a partir de la misma actividad artístico-educativa con los siguientes procedimientos:

\section{Observaciones y diario de campo}

Las observaciones se anotaban en el diario de campo después de la impartición de las clases. Se describía la jornada en general en el grupo, rescatando los aspectos más destacados e importantes para la investigación, momento en el que era posible que surgieran datos no esperados sobre las relaciones entre los miembros de la comunidad, su vinculación con la investigadora, la actitud y disposición de los niños, de los maestros y todo lo que se puede descubrir, percibir y memorizar del contexto, los primeros análisis, impresiones, entre otras cosas.

\section{Entrevistas, evaluaciones grupales y registros}

Se hicieron entrevistas a los alumnos, pero sobre todo a los maestros de los dos grupos, con quienes se trabajó en su calidad de informantes de los procesos, considerando lo que vieron y sintieron a partir de las intervenciones artístico-educativas, si percibieron cambios en la manera de aprender y la estimulación de los niños, las problemáticas del grupo, la escuela, el contexto, el pasado y presente de la comunidad. Asimismo, se entrevistó a varios padres de familia que tuvieron el tiempo y la disposición para, de esta manera, saber desde el ámbito del hogar, qué significan las clases de arte para los niños, además de triangular y corroborar la información ya generada y conocer mejor algunos contextos familiares por la relevancia que tienen éstos en el desempeño de los alumnos. 
Para las evaluaciones grupales, se mostraban a los alumnos, al final de cada curso, referentes o imágenes sobre los conceptos, procesos y resultados obtenidos con las intervenciones artísticas, a partir de los cuales se les hacían preguntas orales en grupo para establecer los aprendizajes obtenidos.

Además de esto, se pueden agregar aquí varios elementos que sirvieron para el análisis y que son recursos didácticos como las planeaciones y las presentaciones en PowerPoint que se mostraban a los alumnos. Los registros, sobre todo las fotografías, las audio-grabaciones y los videos fueron de vital importancia como evidencia tanto de los procesos, como de los resultados.

\section{ANÁLISIS E INTERPRETACIÓN}

\section{Descripción, narración e interpretación}

Para ordenar y analizar la información se utilizó la narración y la descripción, ya que son las que materializan la experiencia en el trabajo de campo y la dotan de sentido. La etnografía es muchas veces descripción, pero una profunda que busca captar y plasmar, más allá de lo evidente, ambientes, contextos, actitudes, problemáticas y acciones en el lugar de los hechos que se están investigando. Es lo que Clifford Geertz llama descripción densa en su libro La interpretación de las culturas, donde parte de la idea de que la cultura y los grupos humanos generan estructuras de significación que el etnógrafo ha de interpretar. De ahí la importancia de la descripción, más allá de sólo enumerar los hechos ocurridos, pues en ella se desentrańa parte de lo que Geertz (1987, p. 24) llama:

Una multiplicidad de estructuras conceptuales complejas, muchas de las cuales están superpuestas o entrelazadas entre sí, estructuras que son al mismo tiempo extrańas, irregulares, no explícitas y a las cuales el etnógrafo debe ingeniarse de alguna manera, para captarlas primero y explicarlas después.

Las descripciones y narraciones dan así lugar a la interpretación. En su libro Investigación con estudio de casos, R. E. Stake 
(2010) explica que en el análisis e interpretación de los estudios de casos se utilizan dos estrategias que se pueden combinar, es decir, que no son excluyentes y que él identifica con técnicas cualitativas y cuantitativas, pero no como estos términos se entienden en el sentido académico más tradicional. Para él, estas técnicas responden más bien a diferentes procesos de pensamiento al interpretar los fenómenos. Por ejemplo, las técnicas cualitativas se centran en la interpretación directa de los fenómenos o datos individuales y les dan significado; se trata de lo que Stake (2010) llama interpretaciones directas, mientras que las técnicas cuantitativas, también según este autor, buscan relaciones entre los datos para determinar categorías, diversidad de ejemplos y constantes que, sumándose, también dotan de sentido a la información y por ello llevan el nombre de suma categórica. Por ejemplo, si bien la descripción de diversas actividades aparece como cualitativa por su carácter individual y profundo (interpretación directa), su interpretación, si encuentra constantes o ejemplos que se repiten en otros trabajos, actividades, sucesos o contextos y los analiza, se vuelve de tipo cuantitativo (suma categórica). Esta técnica de suma categórica, cuantitativa, acumulativa y sumatoria así explicada por Stake (2010) puede resultar bastante esclarecedora en cuanto a examinar fenómenos o acontecimientos que se repiten varias veces en los procesos y en los resultados y que, en dado caso, pueden hasta conformar porcentajes, constantes, semejanzas y categorías de análisis.

\section{La triangulación como estrategia de verificación y validación de la información}

En la investigación académica se entiende la triangulación como un método o estrategia de controles cruzados de datos para profundizar, verificar y validar informaciones, muchas veces de carácter cualitativo, que involucran a seres humanos, que no son medibles ni mensurables en cifras pero que, como el nombre lo indica, hablan de las cualidades de los fenómenos, sujetos y situaciones, que de otra manera no se podrían evaluar y que son muy relevantes para la comprensión de las problemáticas y de los asuntos medulares de los estudios de esta índole. 
Hay varios autores, entre ellos Norman K. Denzin (2015) y su importante libro sobre investigación cualitativa Manual de la investigación cualitativa, que definen varios tipos de triangulación, incluidas la triangulación metodológica, de datos, geográfica y de personas, entre otras. La triangulación, como estrategia de validación, consiste en comparar y contrastar datos arrojados por diferentes teorías, herramientas de obtención de información o informantes, por ejemplo, y que, coincidiendo con otros datos del mismo tema o problema, permiten verificar y ratificar la información, y si no se corresponden, buscan ampliar y profundizar lo hallado en las diferencias y en los contrastes detectados. Como muy acertadamente comentan al respecto Ruth y Finol (2009, p. 122):

La triangulación en la investigación social presenta muchas ventajas porque al utilizar diferentes métodos, éstos actúan como filtros a través de los cuales se capta la realidad de modo selectivo ... de esta manera proporcionarán al investigador un mayor grado de confianza, minimizando la subjetividad que pudiera existir en cualquier acto de intervención humana.

En el caso de este estudio se utilizaron triangulaciones de personas y geográficas (escuela urbana de Chimalhuacán y escuela rural de la montaña de Guerrero) para validar o ahondar en la información obtenida con diferentes instrumentos, tales como entrevistas a maestros y testimonios registrados de padres de familia, así como el propio análisis e interpretación de los productos artísticos, hechos con base en los criterios analíticos-interpretativos de evaluación que se establecen más adelante.

Así entonces, gracias a estos instrumentos y métodos de recopilación de datos, descripción, análisis e interpretación y desde la particular perspectiva teórico-metodológica que da la etnografía educativa, se abordó el trabajo de campo en las escuelas estudiadas y se realizaron los estudios de caso, buscando siempre integrar la teoría con la práctica, así como los diversos aspectos, ángulos, visiones y voces de los actores involucrados a lo largo de la investigación. 


\section{TEORÍAS PARA EL DESARROLLO ARTÍSTICO Y CURRICULAR}

Arthur D. Efland (2002) establece en su obra Una historia de la educación del arte, cuatro principales corrientes ideológicas en la educación artística, representadas, cada una de ellas, por diferentes movimientos y tendencias que reflejan el contexto histórico-social del momento en que se producen y que se van transformando a lo largo de los siglos XX y XXI. Éstas son: la expresiva y para la paz, la reconstruccionista social, la educativa, conocida como enseñanza a través del arte, y la racional cientificista. Para los desarrollos aquí estudiados, se utilizaron las corrientes expresiva y por la paz para promover y evaluar el desarrollo artístico y la educación a través del arte para el desarrollo curricular, que a continuación se explican más ampliamente.

\section{Desarrollo artístico: corriente expresiva y por la paz}

Tanto la autoexpresión creativa infantil, representada principalmente por Viktor Lowenfeld (1903-1960), como la educación artística de los niños por la libertad y la paz desarrollada por Herbert Read (1893-1968), parten del principio de cambiar al individuo, en este caso el niño, a través de la expresión y la libertad artística, para poder después transformar y mejorar la sociedad en la que viven.

En su libro Desarrollo de la capacidad creadora (1980) Lowenfeld enfatiza el sentido holístico que debe tener la educación y el papel fundamental que para lograrlo tiene la educación artística en la infancia y en sus procesos, a nivel de las sensaciones, los sentimientos y los pensamientos que le estimula e implementa, así como en la identificación con su medio y consigo mismos por medio de la representación y de la creación visual.

A través de la realización de la expresión artística, el niño integra diferentes aspectos de la experiencia que está viviendo y aprendiendo en una manifestación plástica personal que le permitirá apropiarse como un todo de los conceptos, sensaciones e imágenes que esta experiencia suscita en él. Al expresar en la representación artística lo que para él significa un determinado fenómeno, autoexpresa, de igual forma, quién es él mismo en 
relación con lo que representa, se identifica con este mundo fenoménico, se ubica en él y le otorga un significado único, personal y subjetivo que conformará una parte esencial de su identidad y de su estar en la vida (Lowenfeld, 1980, pp. 22-27).

Por su parte, Herbert Read (1982), en Educación por el arte, considera que gran parte de los problemas sociales se deben a la falta de libertad y al enajenamiento del hombre moderno, provenientes, en parte, de una educación basada únicamente en el raciocinio y en el logos, lo que produce una represión de emociones, sensaciones y sentimientos que enferman al ser humano. Partiendo de las ideas de Platón, Rousseau, Dewey y otros, el autor está convencido de la importante contribución que el arte puede tener en la integración de seres libres, que concilien lo interior con lo exterior, lo subjetivo con lo objetivo, lo individual con lo comunitario para ayudar a conformar un mundo mejor, más libre y pacífico ya que para él:

Las gigantescas catástrofes que nos amenazan no son sucesos de naturaleza fundamentalmente física o biológica, sino que son eventos psíquicos. Nos enfrentamos a amenazas horribles derivadas de unas guerras y unas revoluciones que no son más que epidemias psicológicas ... El secreto de todas nuestras enfermedades colectivas debe buscarse en la supresión de la capacidad del individuo para la creación espontánea ... ¡Las tendencias destructivas son el resultado de una vida no vivida! (Efland, 2002, p. 342).

A partir de las teorías y propuestas de Viktor Lowenfeld, Herbert Read y del arte en general se estableció una serie de criterios analíticos-interpretativos para evaluar cualitativamente el desarrollo artístico de los niños:

- La expresividad: la fuerza expresiva, la línea, el trazo, los colores.

- La composición: la utilización del espacio, la integración espacial de los elementos compositivos.

- La creatividad: la originalidad en la selección de los temas y en la manera de abordarlos y solucionarlos.

- La técnica: su asimilación, aprendizaje y utilización.

- La factura: la forma de resolver el trabajo, los detalles, el acabado.

- Los procesos en sí mismos: se refiere a lo que sucede tan- 
to visual, motriz como emocional e intelectualmente en los alumnos al elaborar las actividades más que al producto final. En la realización de los trabajos el alumno observa, siente, crea, inventa, se vincula, socializa, se expresa, aprende, resuelve y todo ello resulta una parte fundamental de la educación artística.

\section{Desarrollo curricular: Corriente de educación a través del arte}

Desde el pragmatismo de John Dewey (2008) de los años treinta que, además de ver la experiencia artística como una forma de intensificar la experiencia vital, buscaba la aplicación del conocimiento teórico a la vida práctica, interrelacionando el arte con las experiencias cotidianas de los alumnos, así como con otras materias de aprendizaje, se fueron sucediendo y retomando continuamente estos esfuerzos por integrar la educación artística a diferentes temáticas y materias curriculares.

Ya desde los ańos cuarenta surge un fenómeno en la pedagogía del arte con diferentes nombres, como currículo integrado o transversalidad curricular, y que busca, a través de actividades e intervenciones artística-educativas, entrelazar e interrelacionar materias escolares de diferente índole propias del programa de estudios para producir en el alumno otro tipo de conocimientos curriculares por medio de estos proyectos artísticos, dando lugar a lo que se conoce como la corriente de educación a través del arte. Esta corriente, al trabajar diversas temáticas del programa de estudios por medio de proyectos de arte diseñados especialmente para ellas, define en esta investigación el desarrollo curricular o académico de los nińos investigados, evaluando el aprendizaje de estas temáticas y materias gracias a las actividades artístico-educativas implementadas. Los procesos y operaciones de pensamiento que se evalúan para el desarrollo curricular en las intervenciones artístico-educativas realizadas con los nińos indígenas a partir de la teoría de la educación a través del arte son:

- La integración entre experiencia y conocimiento por medio de la actividad de arte.

- El juego: lo lúdico como medio de aprendizaje. 
EDUCACIÓN ARTÍSTICA-VISUAL EN NIÑOS INDÍGENAS VULNERABLES. UNA INVESTIGACIÓN...

- La transversalidad: el aprendizaje de diferentes temáticas por medio del arte.

- La apropiación: manejo de la información curricular gracias a la actividad artística.

- La toma de decisiones: ¿qué hacer, por qué y para qué?

\section{COMPARATIVA Y RESULTADOS EJEMPLIFICADOS}

Como consecuencia de la aplicación de las teorías arriba revisadas en el trabajo de campo y de la utilización de las intervenciones artísticas y de la metodología etnográfica con doble estudio de casos y su comparativa, surgieron ricos y variados resultados que se comentan aquí, no sin antes presentar brevemente los contextos donde se realizó la investigación.

El estudio de caso número 1 se llevó a cabo en un grupo de $2^{\circ}$ de una escuela indígena urbana del municipio de Chimalhuacán, en el Estado de México, con el acompañamiento de su maestra. Chimalhuacán es una ciudad dormitorio de nivel socioeconómico bajo, donde la mayoría de la población adulta trabaja en la Ciudad de México y es migrante proveniente de diferentes estados del interior de la República en busca de mejores condiciones de vida. El estudio de caso número 2 se hizo, asimismo, con un grupo de $2^{\circ}$, también con la compañía de su maestra, en la comunidad de Colombia de Guadalupe, Malinaltepec, Guerrero, donde la población es indígena rural con un nivel económico muy bajo. Los habitantes pertenecen a la etnia me'phaa o tlapaneca, gentilicio que también se aplica a su lengua. Las similitudes y divergencias entre ambos contextos produjeron constantes y categorías de análisis coincidentes con la suma categórica de Stake (2010) ya revisada, como se muestra a continuación y que resultan muy interesantes.

\section{Aprendizajes y entorno: calendarios con mi mes de nacimiento}

Fue muy patente, en ambos contextos, la integración entre experiencia y conocimiento por medio de actividades plásticas produciendo aprendizajes significativos, y esto se pudo constatar, por poner un ejemplo muy elocuente, en un ejercicio que consistió 
en realizar un calendario que reflejara el paso del tiempo y la vida cotidiana del alumno en su localidad. Los alumnos pintaron con plumones de colores un calendario actual, con su día y mes de nacimiento y reflejando su actividad favorita.

En la escuela urbana, varios alumnos pintaron las grandes pendientes que hay en Chimalhuacán, pues son muy características de la zona, y los nińos parecen percibirlas, recordarlas y representarlas kinestésicamente, como ya lo advirtiera también Lowenfeld (1980), es decir, por la sensación corporal, por cómo se siente el cuerpo al experimentar caminando las bajadas o las subidas tan pronunciadas de las calles, y también por la ubicación de las casas y edificios que ellos muestran no verticalmente, sino en dirección de estas subidas y bajadas (Figura 2).

FIGURA 2. Calendarios con su mes de nacimiento realizados en Chimalhuacán, Estado de México
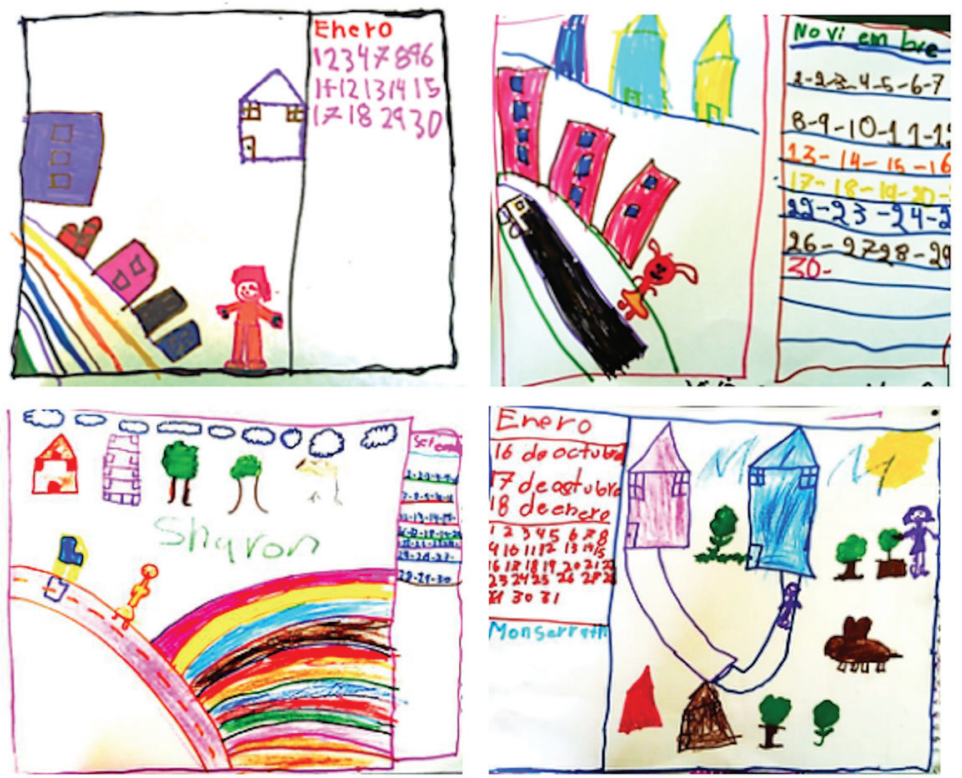

Esto, de nuevo, nos hace reflexionar sobre el lugar del cuerpo y de las sensaciones corporales en la generación de procesos de 
conocimiento empírico en el niño a partir de su realidad. A través de los dibujos y pinturas con plumones, los niños nos hablan de su contexto físico, cómo lo viven ellos a partir de su experiencia y cómo lo significan:

El dibujo, la pintura o la construcción constituyen un proceso complejo en que el niño reúne diversos elementos de su experiencia para formar un todo con un nuevo significado. En el proceso de seleccionar, interpretar y reformar esos elementos, el niño nos da algo más que un dibujo o una escultura; nos proporciona una parte de sí mismo: cómo piensa, cómo siente y cómo ve (Lowenfeld, 1980, p. 15).

Por su lado, lo que más llama la atención de las representaciones del calendario contemporáneo de los niños de la montańa de Guerrero es la presencia constante de la naturaleza vinculada a su vida diaria, a su cotidianidad contextual y, en este caso, a su identidad indígena, que los hace concebirse como hijos de la madre tierra, a la que aún están sujetos umbilical y ontológicamente. Viendo jugar libremente, en un receso, a varios nińos de este grupo de $2^{\circ}$ de la montańa, se trepaban a un árbol y cada uno de ellos era una fruta que ella o él escogían; alguno de ellos nombraba la fruta, y la niña o el niño que la encarnaba se dejaba caer al suelo como si ya estuviera madura, en eso consistía el juego y lo gozaban enormemente. Lo lúdico se tradujo en una hermosa metáfora de la simbiosis que existe entre esta población campesina y la naturaleza. A la pregunta expresa sobre su actividad favorita para representarla en el calendario, de las 16 pinturas realizadas por los alumnos de Guerrero de este grupo, 14 de ellas (es decir 88\%) estaban relacionadas con elementos naturales u ocupaciones relativas al campo y a la tierra, como sembrar, cosechar, vender frutas y verduras, jugar en los árboles y regar las flores. También aparecen constantemente imágenes como la montaña, diferentes animales, árboles, flores, la milpa, sembradíos y frutas como se puede apreciar en las fotografías (Figura 3).

En el caso de Guerrero, lo más llamativo en cuanto a los aprendizajes adquiridos en la escuela rural gracias a las actividades de educación artística, fue esta continua y constante relación que hacían los alumnos entre ciertos aspectos que revisaban en varios 
ejercicios y su propio contexto, vivencias y experiencias. Si bien, como es bien sabido y así lo atestiguaron maestros de la escuela de Malinaltepec, la educación rural e indígena en México está muy disociada de las realidades y lo que contienen los libros de texto, enfocados más en la hegemonía educativa para contextos urbanos y mestizos, los ejercicios artísticos como los realizados con los calendarios pueden paliar y compensar estas carencias y lagunas educativas, al hacer la información y el conocimiento más empírico y familiar para los alumnos indígenas y del campo en este caso en particular.

FIGURA 3. Calendarios con su mes de nacimiento realizados en Malinaltepec, Guerrero
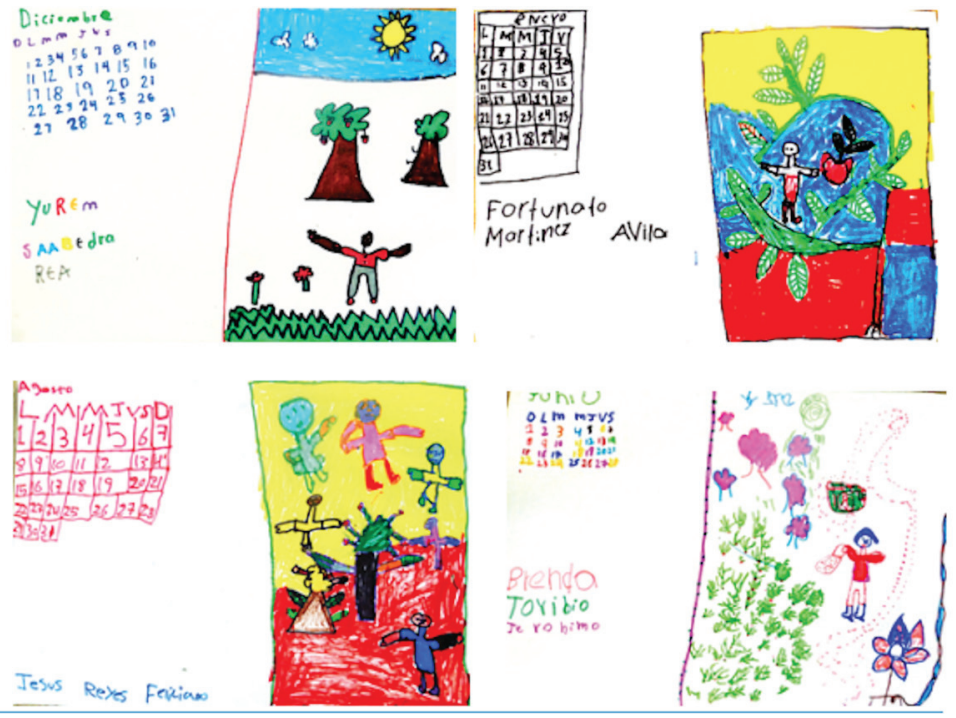

\section{Transversalidad a través del arte: mosaicos sobre la naturaleza en México}

Otro aspecto muy importante que comprobó la investigación fue la pertinencia y validez de la transversalidad en la educación indígena, por medio de proyectos de índole artística, para producir aprendizajes significativos de diferentes contenidos curriculares, 
como se puede ver en el ejemplo de los mosaicos con papel lustre sobre la naturaleza de México.

Para este ejercicio, se habló con los niños sobre los diferentes paisajes naturales en México como montañas, bosques, desiertos, selvas y mares pertenecientes a la materia de Conocimiento del medio de $2^{\circ}$, y la información se apoyó en imágenes fotográficas de esta diversidad natural en una presentación de PowerPoint. Cada alumno escogía un paisaje para interpretar, cortando y rasgando pedacitos de papel lustre para representarlo.

En el grupo de Chimalhuacán, los trabajos terminados muestran una gran comprensión de la técnica del mosaico recién aprendida, así como las diferencias con el dibujo y la pintura en cuanto a procedimiento plástico, posibilidades compositivas y operaciones mentales que implica trabajar con puros trozos de papel (Figura 4). En el audio de la actividad de cierre con el grupo de $2^{\circ}$, con quien se hizo la evaluación grupal, se puede escuchar que, en general, los niños reconocen perfectamente cada uno de los paisajes naturales vistos y realizados en el ejercicio, ya que muchos de ellos, al ver las imágenes de nuevo, contestaron correctamente. Por otro lado, el testimonio de la maestra de este grupo, surgido en una de las entrevistas sobre la integración de lo ya conocido con lo recién aprendido a partir de la experiencia de los niños, puede explicar muy bien de qué manera adquirieron el conocimiento. Asimismo, confirma la relevancia de estas actividades artístico-educativas para generar un aprendizaje significativo y sobre el impacto positivo que estos procesos y formas de trabajo tuvieron tanto en los alumnos como en los mismos maestros:

El mosaico fue algo diferente; tradicionalmente, hacemos maquetas con arbolitos, cochecitos, animalitos comprados, sus recortes pegados, el niño recorta un río y lo pega, recorta un árbol y lo pega, o sea, todo ya hecho ... $\mathrm{y}$ a veces nosotros nos frustramos como maestros, porque queremos que el niño lo haga tal y como le decimos, si ya le salió chueco aquí, "no, no, no, ya estás mal”. Pero cuando les vamos dando esa libertad y esa seguridad, los nińos van entendiendo más y cuando vemos los temas, los contenidos y los trabajamos al revés, a través de hacer, de crear, de observar y ya después llegar de esa manera al contenido, ya trabajar el contenido, pues el 
niño lo recuerda, el niño lo vivió, lo creo, lo manipuló, entonces así ya se le va quedando más.

Esta acertada observación de la maestra sobre el mosaico se vincula con lo expresado por Elliot Eisner (2004) en la video-conferencia ¿Qué puede aprender la educación del arte?, en relación con el hecho de que, en los procesos de creación artística y sus resultados, no existen, como en otros procesos y productos escolares, acierto o error; tampoco está bien o mal, permitiendo la resolución de problemas desde diferentes ángulos y de distintas maneras, como a menudo ocurre en las problemáticas de la vida real, que no tienen una solución unívoca. Esto da lugar a la estimulación de importantísimas herramientas mentales, así como a la motivación e implementación en los niños de un pensamiento individual, original y múltiple, tan valorizado hoy en día, y que se conoce como pensamiento lateral o divergente.

FIGURA 4. Mosaicos con papel lustre realizados por los niños urbanos de Chimalhuacán, Estado de México
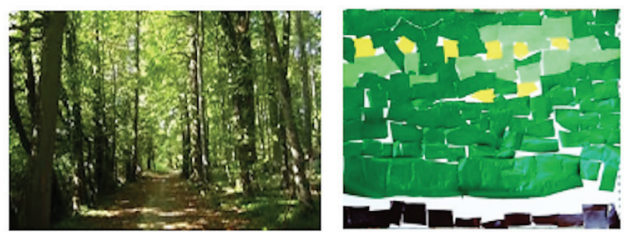

El bosque: foto que se les mostró e interpretación de un niño.
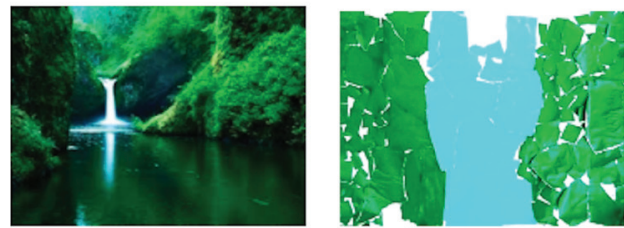

La selva: foto que se les mostró e interpretación de un niño.
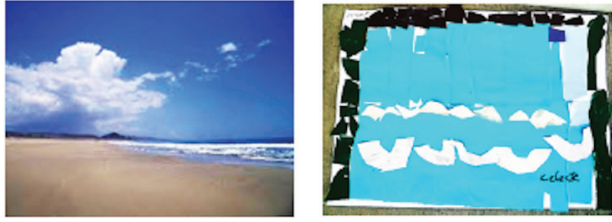

El océano: foto que se les mostró e interpretación de una niña. 
En el grupo de Guerrero, aunque el desempeño fue algo desigual, sobre todo por los ritmos de trabajo, y algunas composiciones que quedaron inconclusas, en general trabajaron bastante bien demostrando un adecuado entendimiento global de la actividad.

De nuevo, en varios de los trabajos destaca la gran capacidad de síntesis desplegada por los niños y que la técnica del mosaico favorece, ya que permite recrear con gran sencillez lo percibido. Las interpretaciones revelan esquematizaciones claras, sólidas y creativas, y sugieren una audaz e imaginativa comprensión visual de las formas. Todo este ejercicio se basa en gran parte en la interpretación visual del mundo y de las imágenes que rodean a los alumnos y fue una amplia demostración de ello. Los niños vincularon continua y creativamente lo que ya sabían de la naturaleza de México y de su medio con lo que vieron en las imágenes del PowerPoint y lo que la actividad les proponía. Respecto a esto, destaca la interpretación de la montaña que hizo una nińa de la escuela rural de Malinaltepec ya que, por los colores utilizados, parece interpretar su propia montańa de Guerrero tal como se ve desde allí, que ella conoce y es donde vive, y no la montańa mostrada en el Power Point, como lo hicieran todos los niños de la ciudad que escogieron este paisaje para representar (Figura 5).

Escuchando el audio de la evaluación final realizada unos meses después de que hicieran el mosaico, los niños indígenas rurales contestaban al unísono cuáles eran los diferentes paisajes de la naturaleza del país revisados en el ejercicio, confirmando así el aprendizaje significativo que generaron a partir de la actividad. De igual manera, varios de ellos identificaron las acciones de recortar los papeles y pegarlos para hacer el mosaico.

Tanto en el medio urbano como en el rural, en este ejercicio se perciben claramente algunos procesos de pensamiento que suceden en los niños de esta edad (es decir, entre los siete y los nueve ańos) al ver una imagen fotográfica tomada de la realidad, vista sólo por un momento y la interpretación que ellos hacen al trasladarla al papel y con determinado material, es decir, con cuadritos de papel tipo mosaico. En los procesos mentales desarrollados hay síntesis, abstracción, invención, asimilación y organización de la información visual, para recrearla en algo nuevo y personal relacionado con los conceptos y contenidos aprendidos 
y con las propias vivencias y nos hablan de habilidades, capacidades y potencialidades de los niños más allá del lenguaje escrito y discursivo.

\section{FIGURA 5. Montaña}
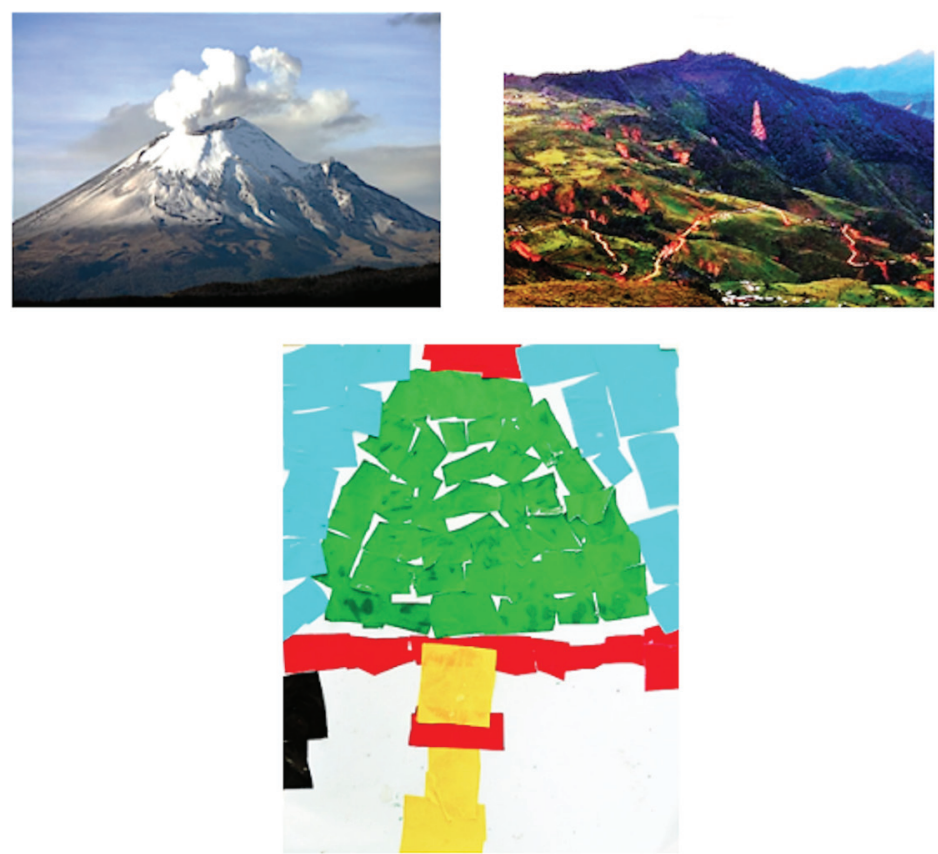

Nota. A la izquierda aparece la foto que se les mostró a los niños, a la derecha una foto de la montaña de Guerrero que no vieron en el PowerPoint y abajo la interpretación de una niña que se parece más a la segunda foto que no vio.

\section{Desarrollo artístico: mural sobre mi escuela}

Por medio del ejemplo del mural sobre su escuela realizado por los alumnos, se puede apreciar muy bien cómo este tipo de proyectos estimula e implementa el sentido artístico, creativo y estético de los niños. El mural consistió en representar visualmente su escuela, en un espacio grande de papel kraft y se realizó en tres fases: la primera fue de reconocimiento, por equipos, de su espacio escolar desde diferentes puntos y bocetarlo con lápices de grafito; en la segunda, también por equipos, coloreaban los bo- 
cetos con plumones, lápices y crayones de colores, y en la tercera y última, todo el grupo, acordando, consensuando y tomando decisiones, se ponía de acuerdo para integrar el producto final con pinturas y dibujos cortados y pegados tipo collage.

En Chimalhuacán, el desarrollo artístico de este ejercicio fue muy amplio y abarcó diferentes aspectos y dimensiones (Figura 6). Dominan los grises como los de la mayoría de los muros de la escuela y de la zona, pues es un tipo de tabique de cemento y concreto muy utilizado por allí y esto, una vez más, refleja la vivencia y representación del contexto por parte de los niños. Abundan también los azules, verdes y amarillos. En una parte del mural aparecen figuras humanas como invertidas, pues están al revés de todo lo demás del mural; sin embargo, responden al sistema de "doblado hacia arriba". Muchas veces, en esta edad, cuando el niño trabaja sobre el suelo, puede tener una perspectiva global de la composición, y desde todas las direcciones representa subjetivamente la simultaneidad de lo que ve y conoce, y lo sitúa alrededor de la hoja; esto se acentúa cuando es pintado entre varios niños (Lowenfeld, 1980).

Las diferentes técnicas utilizadas ya habían sido trabajadas a lo largo de todo el curso y se combinaron para manifestar también una variedad de texturas, tipo de trazos, vigor y expresividad, tonalidades y factura que favorecieron mucho plástica y visualmente la composición. El ejercicio fue una manera de evaluar su aprendizaje y asimilación: supieron manejar muy bien estas técnicas y materiales y los mezclaron, intuitivamente, de la mejor manera, para sacarles el mayor provecho artístico. Si apreciamos el nivel de complejidad, podemos notar en el mural una composición muy rica que combina abstracción y figuración con esquemas completos y bien elaborados detalles, así como una utilización del espacio coherente y completa que muestra el tema y sus elementos en su totalidad, como un todo bien acabado. La sintaxis o estructura del mural, que decidieron entre todos los alumnos, sin intervención de los adultos, es equilibrada, sólida y armoniosa, es decir, visualmente se sostiene y es agradable a la vista. 
FIGURA 6. Mural colectivo representando la escuela urbana de Chimalhuacán, Estado de México

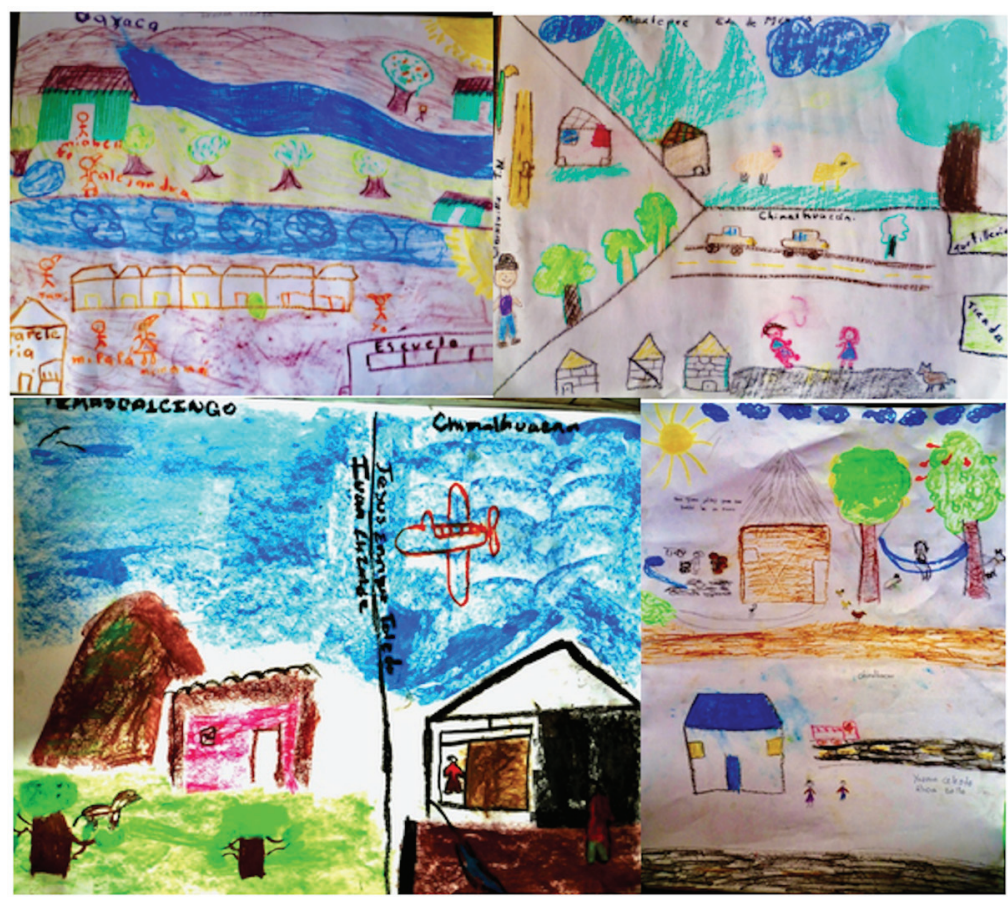

En Malinaltepec, Guerrero, en este ejercicio, los niños revisaron también las técnicas aprendidas hasta ese momento como crayones de cera, plumones de colores, dibujo a lápiz, pinturas acrílicas y collage.

Experimentaron con la combinación de todas ellas y demostraron que las habían aprendido y asimilado muy bien para saberlas utilizar de nuevo en diferentes situaciones.

En la primera fase del dibujo a lápiz sobre cartulina, de la misma manera en que se hizo en la escuela de Chimalhuacán, algunos equipos dibujaron afuera copiando directamente lo que estaban viendo y otros dibujaron dentro, representando las imágenes a partir de su memoria e imaginación. A la hora de las entrevistas-evaluaciones que se les hicieron, se puede constatar que varios niños, aunque no todos, eran conscientes de su proceso de elaboración de las imágenes ya fuera a partir de lo visto, de 
lo recordado o de lo imaginado. Los resultados, en realidad, no varían mucho, y a esta edad de la infancia, las imágenes se construyen en general a partir de las tres acciones de observar, hacer memoria e inventar o imaginar.

Otro aspecto en el ámbito de lo artístico que les permitió explorar la actividad del mural fue pintar en gran formato. En el papel kraft de $3 \times 1$ m., los niños, aunque algo apretados, sí podían visualizar, expandirse y experimentar una dimensión espacial mucho más grande de la que normalmente están acostumbrados.

FIGURA 7. Mural colectivo representando la escuela rural de Malinaltepec, Guerrero

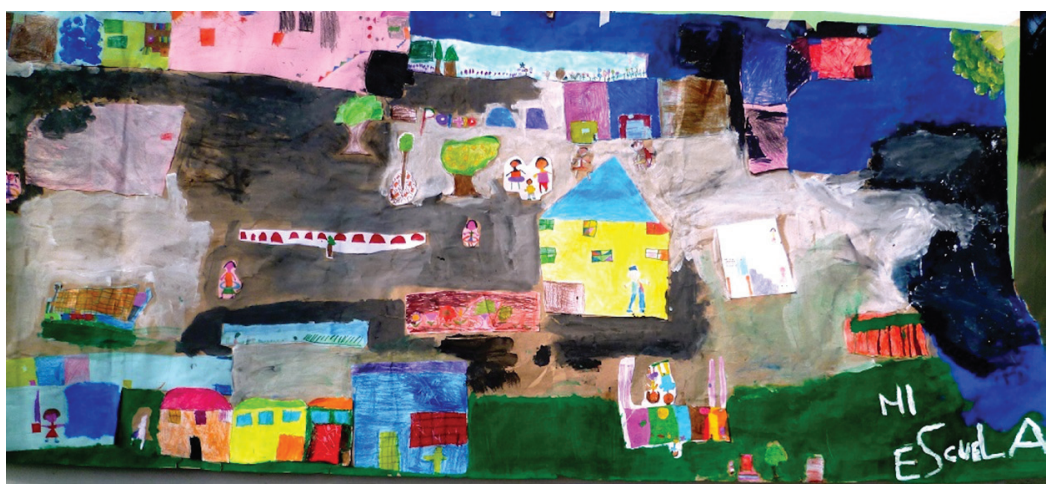

Los colores predominantes en el trabajo de los niños de Guerrero fueron el verde, el café, el azul y el naranja, correspondientes a colores de la escuela pero, de nuevo, también son colores de su entorno y de los paisajes naturales que los rodean. La composición y el esquema del mural de la escuela son complejos, con varios elementos y técnicas para integrar en un espacio amplio y fueron resueltos por ellos mismos de manera armónica y expresiva a la vez, con un orden establecido donde aparecen el comedor, la cancha de basquetbol, el patio, los salones. Los alumnos demostraron una gran comprensión del espacio y su distribución es ordenada y estable. Como en la escuela de Chimalhuacán, utilizaron el sistema del "doblado hacia arriba", que permite ver la pintura desde arriba y desde abajo y que es mencionado por Lowenfeld, quien lo define como "el proceso de crear un 
concepto de espacio dibujando los objetos perpendicularmente a la línea base, aun cuando parezca que estos objetos están dibujados de forma invertida" (Lowenfeld, 1980, p. 181). Este sistema refleja perfectamente la experiencia subjetiva de los niños en el acto de pintar y que los hace ubicarse, a todos y a cada uno de los que están trabajando, en el centro de la escena.

\section{Fortalecimiento socioemocional y afectivo: trabajo con gises mojados con mis familiares}

La importancia de este ejercicio reside, sobre todo, en el aspecto procesual, en la interacción, convivencia, intercambio de experiencias y vinculación entre padres e hijos, así como entre los alumnos, los padres de familia, las maestras y el grupo.

Los niños se pusieron a trabajar con sus familiares, hablaron con ellos y pintaron en una cartulina con gises mojados. La actividad fortaleció la comunicación entre padres e hijos en una temática esencial para entender su origen e identidad, como es la del fenómeno de la migración. Varios representaron solamente algún recuerdo del pueblo de origen en el campo, muchos de ellos, los animales, la flora, los paisajes y, por supuesto, la familia. Otros pintaron ambos lugares, el de origen y donde viven actualmente, es decir Chimalhuacán, y se ve en algunas de estas representaciones la diferencia de paisaje cuando es rural o es urbano (Figura 8). Resulta llamativo observar en las pinturas que representan ambos lugares, el rural y el urbano, cómo varios signos o símbolos que caracterizan alguno de los dos contextos se repiten. Así, por ejemplo, animales de granja, árboles y color verde, montes, ríos y cabañas significan el campo y aparecen en varios de ellos; los coches, el tren ligero, aviones, edificios y calles ilustran el medio urbano, invitándonos a reconocer visualmente ambos contextos.

Al entrevistar a algunas madres sobre cómo habían sentido el ejercicio, si las había acercado a sus hijos y qué pensaban de todo ello, todas coincidieron en que los había acercado y expusieron lo que la narración, los recuerdos y la pintura realizada conjuntamente generaron en ellos. He aquí dos testimonios seleccionados por su relevancia en relación con lo dicho: 
EDUCACIÓN ARTÍSTICA-VISUAL EN NIÑOS INDÍGENAS VULNERABLES. UNA INVESTIGACIÓN...

Sí, sí nos acercó. Sentí emoción pues es una bonita actividad el trabajar con sus hijos en la escuela, a veces por el trabajo no da mucho tiempo, pero en esos ratitos que está uno con ellos, es bonito.

Soy de Oaxaca. Aquí conocí a su papá y aquí nacieron ellos. Mi pueblo se llama San Juanito. Vamos a visitar cuando se puede. Le dije a mi hijo así vivía antes, eso es lo que jugué antes, ésta es mi casa, donde vivíamos antes, aquí era donde yo iba a lavar, y bueno eso...le estuve explicando y lo voy haciendo (la pintura). Uno siente bonito al recordarlo, al platicar a tus hijos qué es lo que jugaste, cómo viviste, cómo anduviste y todo eso.

FIGURA 8. Trabajos con los padres en Chimalhuacán sobre lugar de origen y migración

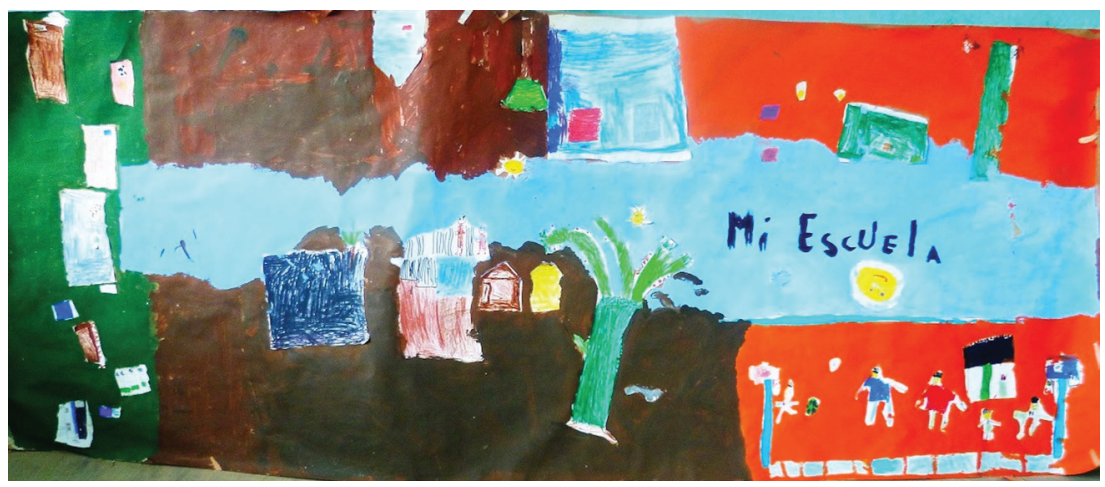

Como se puede apreciar aquí, la actividad tuvo en las personas involucradas un fuerte impacto positivo y un fortalecimiento del vínculo familiar, al rememorar, junto con sus hijos o nietos su propio origen, historia, pasado y presente, algunas veces conociendo el niño el referente del pueblo o comunidad y otras no. Los niños aprendieron sobre el contexto originario de los padres y de la familia a través de la experiencia de la narración oral de las vivencias personales, así como de la educación artística en el trabajo plástico que realizaron al alimón. Asimismo, compartieron con los familiares un tiempo de calidad, de comunicación y de reconocimiento mutuo. Por otro lado, la misma temática y el ambiente alegre y de acompańamiento que se dieron durante la actividad contribuyeron a que se compartieran experiencias e 
identificaciones entre los participantes, como el venir de otro lugar de la República, lo que fortaleció el vínculo comunitario del grupo. De esta manera, respondiendo a la triangulación metodológica de personas ya explicada anteriormente para validar los datos, toda esta información se corroboró comparándola con las entrevistas a las dos maestras del grupo de $2^{\circ}$ de ambos contextos, el de Chimalhuacán y el de Guerrero, quienes confirmaron que ellas también observaron este fortalecimiento de los vínculos familiares y comunitarios que se dio gracias a las actividades artísticas realizadas en conjunto con los padres y con el grupo.

En la localidad de la montańa de Guerrero el fenómeno de la migración no es tan común, por lo que se decidió mejor trabajar con los familiares el tema de su propia localidad. Unicamente pudieron llegar cuatro padres de familia, por lo que se formaron equipos con cinco niños cada uno más un adulto. Se les pidió que escogieran un tema que tuviera que ver con su tierra, su pueblo, alguna tradición, fiesta, paisaje o lugar que les gustara mucho. Pintaron la montaña con árboles, animales varios como jabalíes, culebras, pájaros, alacranes y otros de la zona. Hicieron también el tema de la navidad y el de la escuela. Otro equipo representó la fiesta grande de enero, con el rodeo o jaripeo y el castillo de juegos pirotécnicos (Figura 9). Al final se hizo pasar a los alumnos al frente y explicar, por equipo, lo que habían pintado, reforzando la expresión oral y la autoestima al ser escuchados por los adultos y parientes.

Los niños que trabajaron con los padres lo disfrutaron enormemente y estuvieron muy motivados; los progenitores se enteraron mejor de lo que hacen sus hijos en la escuela y convivieron con ellos de una manera diferente de la habitual. Los niños cuyos padres no fueron, casi la mayoría, también participaron gustosos con los otros niños y con los adultos. Era la primera vez que los alumnos trabajaban de esta manera, interactuando con padres y adultos y se les notó muy estimulados, creativos y bien integrados. En lo grupal, la actividad favoreció mucho la socialización y el trabajo en equipo armonioso, colaborativo y productivo y entre todos los miembros de cada equipo se pusieron de acuerdo, decidieron y organizaron el trabajo. 
EDUCACIÓN ARTÍSTICA-VISUAL EN NIÑOS INDÍGENAS VULNERABLES. UNA INVESTIGACIÓN...

Los temas y su representación impulsaron el conocimiento y valoración de su propio contexto comunitario y de la cohesión identitaria. Al pintar su localidad, algunas costumbres, tradiciones y el entorno que todos reconocen, los alumnos visualizaron su mismo lugar de origen y de pertenencia, así como el orgullo de ser parte de ahí. Una vez más es claro cómo los convivios del pueblo, como la fiesta grande de enero o los festejos navideños, tan arraigados entre los pueblos indígenas, consolidan los nexos comunitarios. De nuevo también se puede observar el fuerte lazo con la naturaleza en las imágenes realizadas, en las cuales aparece la omnipresente montaña, la fauna local, los árboles, el río, las flores.

FIGURA 9. Trabajos con los padres en Guerrero sobre su comunidad
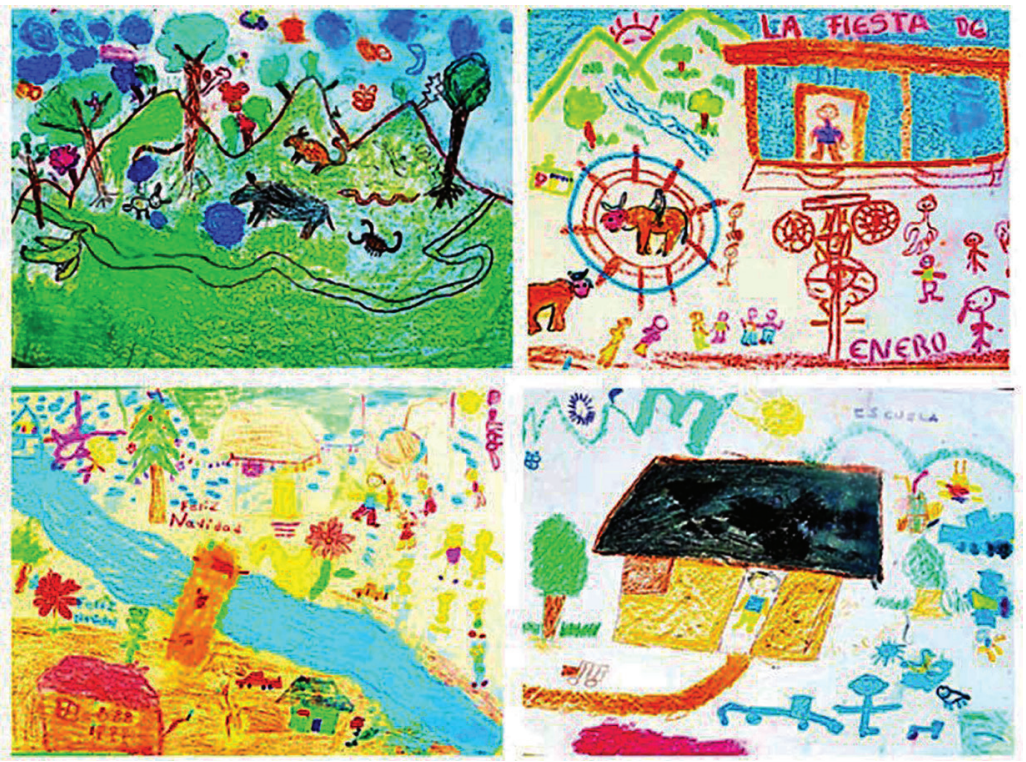

\section{RELEVANCIA Y CONCLUSIONES}

Por medio de la etnografía educativa, las intervenciones artísticas y los estudios de caso con sus respectivos ejemplos, el estudio mostró la aplicación práctica de dos corrientes de la educación 
artística, la expresiva y por la paz y la educación a través del arte, en dos contextos indígenas con características de vulnerabilidad. Estas puestas en uso de la teoría demostraron ser estrategias y herramientas de enseñanza muy pertinentes en estos entornos que favorecieron, interrelacionándose, los desarrollos académicos y artísticos de los alumnos involucrados y que incluso, como se vio, repercutieron en el ámbito socioemocional.

Llamó mucho la atención una constante que apareció en varios ejercicios de educación artística y que fue la forma en que los niños representaban visualmente aspectos de su entorno que ellos consideraban importantes porque tenían que ver con sus propias vivencias. Ejemplos de ello son las calles de Chimalhuacán, con sus pronunciadas pendientes, y que los niños experimentaron y representaron kinestésicamente (Figura 2); el vínculo permanente con la naturaleza y las actividades en relación con ella en la montaña de Guerrero (Figuras 3, 5 y 9); el conocimiento de la vida urbana y rural de los niños de origen migrante de Chimalhuacán (Figura 8); las tradiciones, fiestas, paisajes y animales del pueblo en los niños de Guerrero (Figuras 9); los colores y la distribución del espacio en los murales sobre su escuela (Figuras 6 y 7). Desde el punto de vista del desarrollo artístico y retomando a Viktor Lowenfeld y a Herbert Read, la actividad visual en estos casos vendría a completar o a ampliar un conocimiento que los alumnos fueron construyendo desde conceptos, sensaciones, emociones e imágenes (Read, 1982) adquiridos de diferentes fuentes como libros, medios de comunicación, maestros y entre los que uno fundamental es su propio contexto, del cual provienen vivencias y experiencias y que a menudo no es considerado. Esto es muy importante y no deja de relacionarse con la fuerte problemática planteada por Freire (2002) y su noción de la educación bancaria y descontextualizada de los contenidos y entornos de los sectores más oprimidos, cuando programas de estudio, contenidos de libros de texto, materiales didácticos y formación docente, surgidos de la tradición moderna hegemónica y de la búsqueda de una identidad nacional uniformizada, están desconectados de los contextos lingüísticos, culturales y sociales particulares donde se enseñan, en este caso los indígenas. 
Frente a todo ello, al aplicar la educación artística-visual de manera práctica y ligada a los contenidos y realidades de los alumnos, ésta se convirtió en una herramienta valiosísima, en un método muy eficaz e idóneo en el proceso de enseñanza-aprendizaje a la hora de relacionar teoría y práctica, temas del programa de estudios y experiencias, conocimientos locales, empíricos y globales de los alumnos de Chimalhuacán y Guerrero, compensando, de alguna manera, estas lagunas y vacíos curriculares que existen al respecto en el sistema educativo. Otro aspecto que fomentó la educación artística y que mostró la indagación fue la motivación en los contextos de los pueblos originarios, de este pensamiento divergente que genera en los alumnos diferentes posibilidades para la visualización y resolución de problemas escolares y cotidianos que, en última instancia, ampliarán y enriquecerán sus perspectivas, espacios de acción y opciones en la vida.

En cuanto al aspecto relacionado con los vínculos familiares y comunitarios, las actividades que involucraron a los padres o familiares en los dos grupos de ambas escuelas, además de producir hermosos trabajos, fueron muy apreciadas tanto por alumnos como por parientes y maestros, pues generaron un espacio de interacción entre ellos muy sano y constructivo.

Los temas de estos ejercicios, como se vio, se vinculaban generalmente con su propia historia familiar, origen y circunstancias, con su historia de migración o con su comunidad (Figuras 8 y 9), donde las experiencias de los mayores eran transmitidas directamente a los alumnos de su propia voz, de manera oral, en una participación común que propició otras maneras de vincularse entre ellos y comunitariamente. A esto hay que agregar que no es poco común que los padres de familia de estos medios sociales muchas veces no sepan leer ni escribir o que su escolaridad sea muy baja, por lo que no pueden apoyar a sus hijos en este sentido y las actividades conjuntas, como éstas, pueden ayudar a mitigar, de cierta manera, la aflicción que estas carencias y situaciones pueden despertar en el orgullo y la autoestima familiar y en las relaciones intrafamiliares.

Por su parte, la etnografía educativa, como teoría metodológica, probó ser la más adecuada para los objetivos y preguntas de investigación, pues además de permitir aplicar prácticamente 
muchos de los postulados teóricos de las dos corrientes de educación artística revisadas, así como observar procesos y resultados, cumplió con su cometido de dar voz a los principales actores y sujetos de investigación, los niños de las primarias donde se hizo el trabajo de campo, así como a las comunidades educativas de dichas escuelas, a saber maestros y padres de familia.

En cuanto a las limitaciones del trabajo, se podría mencionar una constante preocupación que surgió durante todo el estudio, de cara a una posible y deseable utilización y apropiación por parte de los maestros de las estrategias y herramientas artísticas en sus contextos, fue la provisión de materiales de artes plásticas en localidades y lugares más alejados o desprovistos de recursos económicos para adquirirlos, pues todo el material utilizado se facilitó gratuitamente para el desarrollo de la investigación.

Otro punto de inquietud fue y son las inercias y el desinterés institucionales a nivel nacional, particularmente en la educación pública, por las actividades y las materias de índole artístico-creativas en general. Si bien estas materias sí aparecen consideradas y con propuestas ambiciosas en los programas de estudio de la SEP, el tiempo oficial asignado es de una hora a la semana para todas las disciplinas de arte (teatro, danza, música y artes visuales). Por otro lado, y dada la enorme cantidad de contenidos que los maestros tienen que cubrir en el curso escolar, la realidad es que, en la puesta en práctica, las actividades artísticas no suelen tener mucho espacio de realización ni son valoradas, como no sea para realizar ejercicios de relleno o conmemorativos, convirtiéndolas en un lujo o en un privilegio de sectores socioeconómicamente más favorecidos. En este sentido, la transversalidad y el currículo integrado por medio del arte podría aparecer como una excelente opción tanto para generar un aprendizaje significativo y más motivante en el alumno, cuanto para solventar, compensar y remediar estas inercias y descuidos institucionales, además de implementar el pensamiento y las prácticas artísticas en diferentes entornos socioculturales. 
EDUCACIÓN ARTÍSTICA-VISUAL EN NIÑOS INDÍGENAS VULNERABLES. UNA INVESTIGACIÓN...

\section{REFERENCIAS BIBLIOGRÁFICAS}

Efland, A. (2002). Una historia de la educación del arte. Barcelona, España: Paidós Arte y educación.

Eisner, E. (2004). ¿Qué puede aprender la educación del arte? Recuperado de https://www.youtube.com/ watch?v=yegvXHe4Dno

Clifford, J. (2001). El dilema de la cultura. Antropología, literatura y arte en la perspectiva posmoderna. Barcelona, España: Gedisa.

Denzin, N. K. (2017). Manual de la investigación cualitativa. Vol. IV, Buenos Aires, Argentina: Gedisa.

Dewey, J. (2008). El arte como experiencia. Barcelona, España: Paidós Estética.

Freire, P. (2002). Pedagogía del oprimido. México: Siglo XXI Editores.

Geertz, C. (1987). La interpretación de las culturas. México: Gedisa.

Geertz, C. (1994). Conocimiento local. Ensayos sobre la interpretación de las culturas. Barcelona, España: Paidós Básica.

Lowenfeld, V. (1980). Desarrollo de la capacidad creadora. Buenos Aires, Argentina: Kapelusz.

Lyotard, J. F. (2006). La condición postmoderna. Madrid, España: Cátedra.

Martínez, B. J. et al. (1990). Hacia un enfoque interpretativo de la enseñanza: etnografía y curriculum. Granada, España: Universidad de Granada.

Read, H. (1982). Educación por el arte. Barcelona, España: Paidós Educador.

Rockwell, E. (2009). La experiencia etnográfica. Historia y cultura en los procesos educativos. Buenos Aires, Argentina: Paidós, Voces de la Educación.

Rodríguez Gómez, G. et al. (1996). Metodología de la investigación cualitativa. Málaga, España: Aljibe

Stake, R. (2010). Investigación con estudio de casos. Madrid, España: Morata. 
Vallejo, R. y Finol, M. (2009). La triangulación como instrumento de análisis para las investigaciones educativas. Revista electrónica de humanidades, educación y comunicación social, 7(4). Recuperado de https://dialnet.unirioja.es/servlet/articulo?codigo $=3063110$ 